\title{
A WIDE SPEED RANGE DIRECT TORQUE CONTROL OF INDUCTION MOTORS USING AN IMPROVED HYBRID STATOR FLUX ESTIMATOR SCHEME
}

\author{
Esam E.Wahdan**, M. M Khater*, A. Mobarka*, and A.A. El-Hefnawy* \\ *Department of Electrical Engineering, Faculty of Engineering, \\ Minoufiya University, Shebin El-kom Egypt \\ **International Steel Rolling Mill (ISRM), Al-Sadat City, Minoufiya, Egypt.
}

\begin{abstract}
Direct torque control (DTC) of three phase induction motors allows a high dynamic performance to be obtained with a very simple control scheme. It is based on the stator flux orientation in which the stator flux is used as a main control variable. Therefore in DTC, determination of stator flux is always of first and primary concern. This paper investigates the stator flux estimation problem over the entire speed range. A hybrid stator flux estimator which combines the voltage model and current model with a PI controller is proposed. The proposed method does not depend on the angular speed and reduces the problems associated with pure integrators of voltage model at low speed. An improved stator resistance adaptation scheme is used to enhance the system performance. Thus, the drive system is capable of working from very low speed up to high speed and exhibits good dynamic and steady-state performances. The effectiveness of the proposed scheme is investigated, and good results have been achieved for both steady-state and dynamic operating conditions.

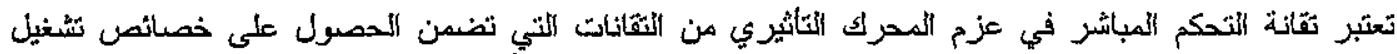

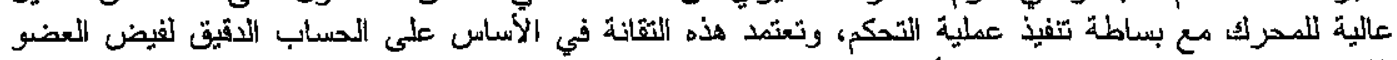

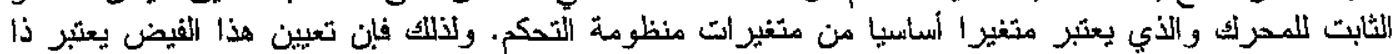

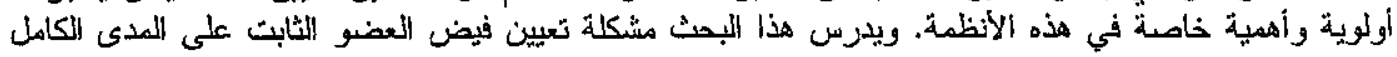

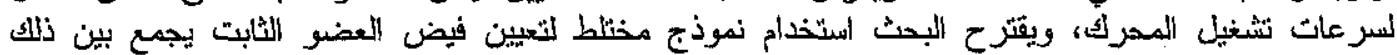

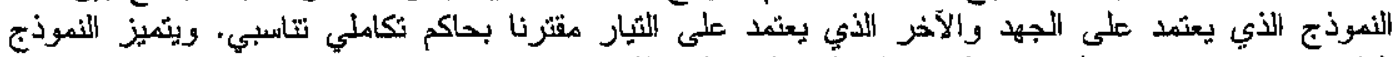

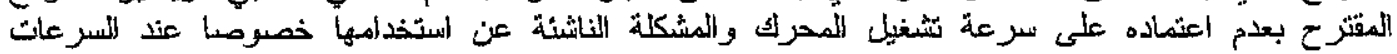

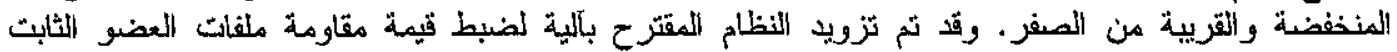

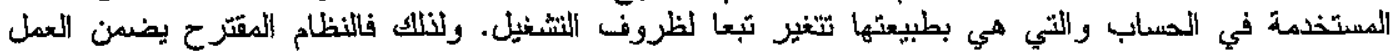

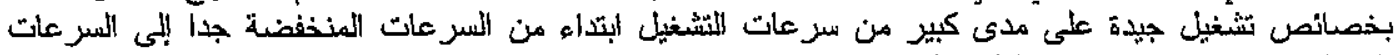

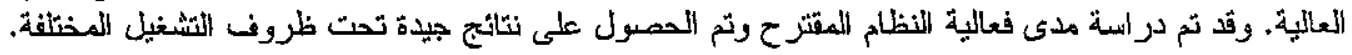

Keywords: Induction motor, direct torque control (DTC), stator flux estimator," stator resistance adaptation

\section{INTRODUCTION}

Due to its ruggedness, maintenance-free operation and many other advantages, the induction motor is considered one of the most widely used motors in variable-speed drive system applications. It has been enhanced by the recent improvements in power electronic devices and microprocessors which allowed easy implementation of sophisticated control techniques. In recent years decoupled flux and torque control of induction motors have greatly increased in high performance industry applications such as paper and steel rolling mills. Among all strategies based on stator flux the direct torque control (DTC) technique is one of the actively researched control systems which have been recognized as viable solution to achieve this requirement. DTC achieves precise and quick torque response without any need of speed or position sensors, coordinate transformation, pulse width modulation (PWM), or current regulators [15].

The basic idea of DTC is to choose the best voltage vector which makes the stator flux rotates and produces the desired torque. During this rotation the amplitude of the stator flux resets within the limit of a pre-defined hysteresis band. Thus, it is almost constant. With a three voltage source inverter, there are six none-zero voltage vectors $\left(\mathrm{V}_{1}-\mathrm{V}_{6}\right)$ and two zero voltage vectors $\left(V_{0}, V_{7}\right)$ which can be applied to 
the machine terminals. A suitable stator voltage vector $\mathrm{V}_{\mathrm{s}}$ is selected from a switching table which is elaborated on the basis of torque and flux hysteresis comparator outputs $\left(\sigma_{t \&} \sigma_{\psi}\right)$ and stator flux angular position $(\mathrm{N})$ as shown in Table 1 .

In a DTC scheme like that shown in Fig.1, it is essential to use the stator flux as one of the control variables. This requires an accurate value of the stator flux to be always accessible during operation. Direct measurement of stator flux via Hall-effect sensors or search coils inserted in the stator slots may be used. This method is supposed to get an accurate value of the stator flux without sensitivity to motor parameters. However, such direct measurement is sometimes difficult, expensive and prone to errors in noisy environments. These difficulties were sufficient to persuade researchers to develop alternative methods for on-line flux estimation based on terminal currents, voltages, and angular speed.

Basically, stator flux can be estimated using either a voltage model or a current model depending on the operating speed. At high speeds, voltage model estimator is very reliable and robust, while current model estimator is quite sensitive to errors of speed measurement. However, at low speeds, current model estimator performs satisfactorily, while voltage model estimator suffers from the noise-sensitive integration and depends heavily on the stator resistance detuning [6]. Various attempts have been made to combine these two estimators in some way to obtain good performance over the entire speed range [7-9]. A low-pass filter was proposed to select the current model at low speeds and switches to the voltage model at high speeds [7]. The introduction of that low-pass filter has the drawback of slow dynamics. An instantaneous hybrid stator flux estimator based on the terminal quantities and motor speed is presented [8]. In that method, the transition from one estimator to the other was dependent upon a selected crossover speed. The choice of this crossover speed is largely dependent on the accuracy of speed measurement or estimation which, in turn, depends on parameter detuning.

The effectiveness of an observer using a hybrid voltage-current flux estimator model depends upon the accuracy of stator resistance. Stator resistance actually changes with operational conditions of the motor such as temperature and frequency variations. A mismatch between the controller set of this resistance and its actual value can initiate system instability. This parameter mismatch also results in nonlinearity between the developed electromagnetic torque and its command value. Under these circumstances, it is extremely necessary to implement a stator resistance adaptation scheme to preserve torque control.

Some adaptation control schemes have been proposed to overcome the problem of stator resistance mismatch [10-13]. Of these schemes, an adaptation for the stator resistance based on the difference between the flux current and its command has been proposed [10]. However, it has a problem in identifying the actual flux current. Another adaptation method based on the steady-state voltage equation was introduced [11]. However, it has the shortcoming of using direct-axis flux linkage which itself is affected by stator resistance variations.

This paper investigates the stator flux estimation problem over the entire speed range of a DTC system for a three-phase induction motor. A hybrid stator flux estimator which combines the voltage model and current model with a PI controller is proposed. This method does not depend on the angular speed and reduces the problems associated with pure integrators of voltage model at low speed. An adaptation scheme for stator resistance is integrated with the proposed estimator. The system is investigated under steady state as well as dynamic operation and simulation results are presented.

Table 1 Switching Table

\begin{tabular}{|c|c|c|c|c|c|c|c|}
\hline \multicolumn{2}{|c|}{ Sector number (N) } & $\mathbf{1}$ & $\mathbf{2}$ & $\mathbf{3}$ & $\mathbf{4}$ & $\mathbf{5}$ & $\mathbf{6}$ \\
\hline \multirow{3}{*}{$\sigma_{\Psi}=1$} & $\sigma_{\mathrm{t}}=\mathbf{1}$ & $\mathrm{V}_{2}$ & $\mathrm{~V}_{3}$ & $\mathrm{~V}_{4}$ & $\mathrm{~V}_{5}$ & $\mathrm{~V}_{6}$ & $\mathrm{~V}_{1}$ \\
\cline { 2 - 9 } & $\sigma_{\mathrm{t}}=\mathbf{0}$ & $\mathrm{V}_{0}$ & $\mathrm{~V}_{7}$ & $\mathrm{~V}_{0}$ & $\mathrm{~V}_{7}$ & $\mathrm{~V}_{0}$ & $\mathrm{~V}_{7}$ \\
\cline { 2 - 9 } & $\sigma_{\mathrm{t}}=-1$ & $\mathrm{~V}_{6}$ & $\mathrm{~V}_{\mathrm{i}}$ & $\mathrm{V}_{2}$ & $\mathrm{~V}_{3}$ & $\mathrm{~V}_{4}$ & $\mathrm{~V}_{5}$ \\
\hline \multirow{3}{*}{$\sigma_{\psi}=\mathbf{0}$} & $\sigma_{\mathrm{t}}=\mathbf{1}$ & $\mathrm{V}_{3}$ & $\mathrm{~V}_{4}$ & $\mathrm{~V}_{5}$ & $\mathrm{~V}_{6}$ & $\mathrm{~V}_{1}$ & $\mathrm{~V}_{2}$ \\
\cline { 2 - 9 } & $\sigma_{\mathrm{t}}=\mathbf{0}$ & $\mathrm{V}_{7}$ & $\mathrm{~V}_{0}$ & $\mathrm{~V}_{7}$ & $\mathrm{~V}_{0}$ & $\mathrm{~V}_{7}$ & $\mathrm{~V}_{0}$ \\
\cline { 2 - 9 } & $\sigma_{\mathrm{t}}=-1$ & $\mathrm{~V}_{5}$ & $\mathrm{~V}_{6}$ & $\mathrm{~V}_{1}$ & $\mathrm{~V}_{2}$ & $\mathrm{~V}_{3}$ & $\mathrm{~V}_{4}$ \\
\hline
\end{tabular}




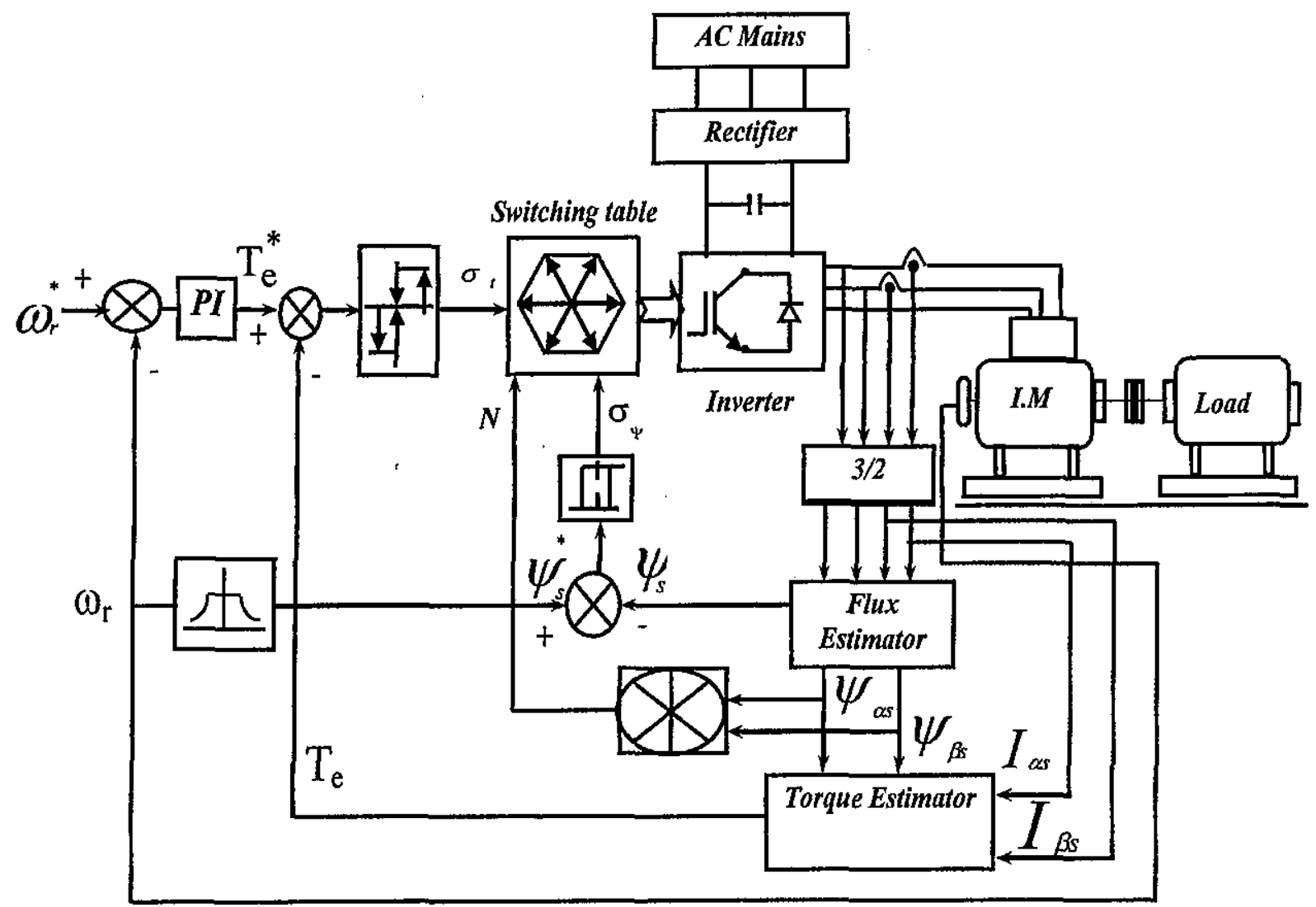

Fig.1 Block diagram of direct torque control for 3-phase induction motor drive.

\section{STATOR FLUX ESTIMATION}

It is important to start with a good and appropriate mathematical model of the induction motor when dealing with stator flux estimation. The dynamic model of the induction motor must incorporate all dynamic effects occurring during steady-state and transient operation. It should also be valid for any arbitrary time variation of voltages and currents generated by the inverter which supplies the machine. The dynamic behavior of an induction motor is described by the following equations written in terms of space vectors in a stator reference frame as:

$$
\begin{aligned}
& \overline{\mathrm{V}}_{s}=\mathrm{R}_{\mathrm{s}} \overline{\mathrm{I}}_{\mathrm{s}}+\frac{\mathrm{d} \bar{\psi}_{\mathrm{s}}}{\mathrm{dt}} \\
& 0=\mathrm{R}_{\mathrm{r}} \overline{\mathrm{I}}_{\mathrm{r}}+\frac{\mathrm{d} \bar{\psi}_{\mathrm{r}}}{\mathrm{dt}}-\mathrm{j} \omega_{\mathrm{r}} \bar{\Psi}_{\mathrm{r}} \\
& \bar{\psi}_{\mathrm{s}}=\mathrm{L}_{\mathrm{s}} \overline{\mathrm{I}}_{\mathrm{s}}+\mathrm{L}_{\mathrm{m}} \overline{\mathrm{I}}_{\mathrm{r}} \\
& \bar{\psi}_{\mathrm{r}}=\mathrm{L}_{\mathrm{r}} \overline{\mathrm{I}}_{\mathrm{r}}+\mathrm{L}_{\mathrm{m}} \overline{\mathrm{I}}_{\mathrm{s}}
\end{aligned}
$$

where

$\overline{\mathrm{V}}_{\mathrm{s}} \quad$ Stator voltage vector;
$\overline{\mathrm{I}}_{s}, \overline{\mathrm{I}}_{\mathrm{r}} \quad$ Stator and rotor current vectors;

$\bar{\psi}_{\mathrm{s}}, \bar{\psi}_{\mathrm{r}} \quad$ Stator and rotor flux vectors;

$R_{s}, R_{r} \quad$ Stator and rotor resistances;

$\mathrm{L}_{\mathrm{s}}, \mathrm{L}_{\mathrm{r}} \quad$ Stator and rotor self-inductances;

$\mathrm{L}_{\mathrm{m}} \quad$ Magnetizing inductance;

$\omega_{\mathrm{r}} \quad$ Rotor angular speed.

\subsection{Stator Flux Estimator Based on Voltage Model}

The simplest and most direct method for determining the stator flux is obtained from Eqn (1) by integration as $[1,14]$ :

$\bar{\psi}_{\mathrm{s}}=\int\left(\overline{\mathrm{V}}_{\mathrm{s}}-\mathrm{R}_{\mathrm{s}} \overline{\mathrm{I}}_{\mathrm{s}}\right) \mathrm{dt}$

This estimator is often referred-to as the voltage model. Although the voltage model estimator is simple and independent of the motor speed or rotor current, it suffers from some problems. One of the major drawbacks is its dependency upon the stator resistance accuracy. Stator resistance is not always constant but actually varies with the motor operational conditions such as temperature rise and 
frequency. At low speeds, the resistive drop $\mathrm{R}_{\mathrm{s}} \overline{\mathrm{I}}_{\mathrm{s}}$ is comparable with the magnitude of the applied voltage, $\bar{V}_{s}$. Therefore, even small errors in the stator resistance can introduce significant errors in the estimated flux. Since there is no feedback mechanism for the stator flux estimator represented by Eqn. (5), and the input of the integrator is a small signal, runaway problems are likely to occur. Thus, the precision of this method is severely compromised [15]. Also, the problems related to the drifting integrators are often pointed out as the flux estimation at low speeds. It is obvious that this method is of no practical use at low speeds due to the previous limitations. At high spéeds, the stator flux estimation is quite insensitive to stator resistance. However, even at high speed, stator resistance detuning can result in inaccurate stator flux estimation.

\subsection{Stator Flux Estimator Based on Current Model}

To eliminate the integrator drift of the previous method, Eqn (3) can be used as a base for the stator flux estimation. This method is often referred to as the current model and it has good properties at low frequencies. However, it also suffers from some other problems. One of its main drawbacks is its need of accurate values of $\mathrm{L}_{\mathrm{s}}$ and $\mathrm{L}_{\mathrm{m}}$. These parameters are always varying and dependent on saturation level of the machine. Another difficulty is the need of the rotor current which usually can not be measured. To overcome such difficulty, the angular speed of the rotor is used to estimate the stator flux. In this way, the stator flux can be estimated using the rotor flux and motor parameters. The rotor flux is obtained from rotor voltage Equation (2). This equation can be rewritten in terms of the stator current and rotor flux as follows:

$$
\frac{d \bar{\psi}_{\mathrm{r}}}{\mathrm{dt}}=\frac{\mathrm{L}_{\mathrm{m}}}{\tau_{\mathrm{r}}} \overline{\mathrm{I}}_{\mathrm{s}}-\bar{\psi}_{\mathrm{r}}\left(\mathrm{j} \omega_{\mathrm{r}}+\frac{1}{\tau_{\mathrm{r}}}\right)
$$

It should be noted that the rotor flux estimation is highly sensitive to variations in the rotor time constant $\tau_{\mathrm{r}}$, which varies with temperature rise. The stator flux is then estimated using the rotor flux as:

$\bar{\psi}_{\mathrm{s}}=\frac{\mathrm{L}_{\mathrm{m}}}{\mathrm{L}_{\mathrm{r}}} \bar{\psi}_{\mathrm{r}}+\sigma \mathrm{L}_{\mathrm{s}} \overline{\mathrm{I}}_{\mathrm{s}}$

where $\sigma$ is the leakage factor and is given by:

$\sigma=1-\frac{\mathrm{L}_{\mathrm{m}}^{2}}{\mathrm{~L}_{\mathrm{s}} \mathrm{L}_{\mathrm{r}}}$
It should be noted that, this type of stator flux estimator has good properties at low speeds; however it is sensitive to parameter errors at high speeds [7]. Also, the rotor speed is essentially required to calculate the stator flux.

\subsection{Stator Flux Estimator Based on a Hybrid Voltage-Current Model}

It is possible to combine the previous two systems in a hybrid voltage-current model for stator flux estimation. This hybrid voltage-current model is represented by the block diagram shown in Fig.2. It contains two models, a current model which is supposed to produce an accurate value at low-speed range, and a voltage model which is supposed to produce an accurate value at high speed range. A. PIcontroller makes a smooth transition between the two models at medium speed based on the error between the two models.

In order to simplify the implementation and to improve accuracy, the rotor flux $\vec{\psi}_{\mathrm{r}}$ (the output of rotor flux current model) is deduced from Eqns (2) and (4) in a rotor flux reference frame $\left(\omega_{\mathrm{e}}=\omega_{\psi \mathrm{r}}\right.$, subscripts " $d q$ ") as:

$\psi_{\mathrm{dr}}^{\mathrm{i}}=\frac{\mathrm{L}_{\mathrm{m}}}{1+\mathrm{p} \tau_{\mathrm{r}}} \mathrm{I}_{\mathrm{ds}}$

$\psi_{\mathrm{qr}}^{\mathrm{i}}=0$

where $\mathrm{p}=\frac{\mathrm{d}}{\mathrm{dt}}$

Also the rotor flux $\bar{\psi}_{\mathrm{r}}^{\mathrm{v}}$ (the output of rotor flux voltage model) is calculated in a stator reference frame (subscript " $\alpha \beta$ ") to estimate the angle $\theta_{\psi \mathrm{r}}$ which is used to transfer from rotor reference frame to stator reference frame and vice versa.

$$
\begin{aligned}
& \psi_{\alpha r}^{v}=\frac{L_{r}}{L_{m}} \psi_{\alpha s}^{v}-\frac{L_{s} L_{r}-L_{m}^{2}}{L_{m}} I_{\alpha s} \\
& \psi_{\beta r}^{v}=\frac{L_{r}}{L_{m}} \psi_{\beta s}^{v}-\frac{L_{s} L_{r}-L_{m}^{2}}{L_{r m}} I_{\beta s} \\
& \theta_{\psi r}=\tan ^{-1} \frac{\psi_{\beta r}^{v}}{\psi_{\alpha r}^{v}}
\end{aligned}
$$

Then the stator flux $\bar{\psi}_{\mathrm{s}}^{\mathrm{i}}$ (the output of stator flux current model) is calculated in a stator reference frame as:

$$
\psi_{\alpha s}^{\mathrm{i}}=\frac{\mathrm{L}_{\mathrm{m}}}{\mathrm{L}_{\mathrm{r}}} \psi_{\alpha \mathrm{r}}^{\mathrm{i}}-\frac{\mathrm{L}_{\mathrm{s}} \mathrm{L}_{\mathrm{r}}-\mathrm{L}_{\mathrm{m}}^{2}}{\mathrm{~L}_{\mathrm{r}}} \mathrm{I}_{\alpha s}
$$




$$
\psi_{\beta s}^{i}=\frac{L_{m}}{L_{r}} \psi_{\beta r}^{i}-\frac{L_{s} L_{r}-L_{m}^{2}}{L_{r}} I_{\beta s}
$$

The stator flux $\bar{\psi}_{s}^{v}$ (the output of stator flux voltage model) is calculated in a stator reference frame based on $\mathrm{Eqn}(1)$ as:

$$
\begin{aligned}
& \Psi_{\alpha s}^{v}=\int\left(\bar{V}_{\alpha s}-R_{s} \bar{I}_{\alpha s}-U_{\alpha s}\right) d t \\
& \Psi_{\beta s}^{v}=\int\left(\bar{V}_{\beta s}-R_{s} \bar{I}_{\beta s}-U_{\beta s}\right) d t
\end{aligned}
$$

In order to correct the estimated value of stator flux, to compensate for the error associated with pure integrator and to provide wide speed range of operation for the entire observer, the stator flux voltage model is adapted through a PI compensator as follows;

$$
\begin{aligned}
& \mathrm{U}_{\mathrm{ds}}=\left(\mathrm{K}_{\mathrm{p}}+\frac{\mathrm{K}_{\mathrm{i}}}{\mathrm{s}}\right)\left(\psi_{\mathrm{ds}}^{\mathrm{v}}-\psi_{\mathrm{ds}}^{\mathrm{i}}\right) \\
& \mathrm{U}_{\mathrm{qs}}=\left(\mathrm{K}_{\mathrm{p}}+\frac{\mathrm{K}_{\mathrm{i}}}{\mathrm{s}}\right)\left(\psi_{\mathrm{qs}}^{\mathrm{v}}-\psi_{\mathrm{qs}}^{\mathrm{i}}\right)
\end{aligned}
$$

The controller parameters $\mathrm{K}_{\mathrm{p}}$ and $\mathrm{K}_{\mathrm{i}}$ may be chosen such that, at low-speed, the current model stands alone, while at high speed the voltage model prevails.

The magnitude of the stator flux vector is,

$$
\left|\psi_{\mathrm{s}}\right|=\sqrt{\psi_{\alpha \mathrm{s}}^{\mathrm{v} 2}+\psi_{\beta \mathrm{s}}^{\mathrm{v} 2}}
$$

and its phase angle is expressed as;

$$
\tilde{\theta}_{s}=\tan ^{-1}\left(\frac{\psi_{\beta s}^{v}}{\psi_{\alpha s}^{v}}\right)
$$

The sector number $(N)$, which depends on the phase angle of the stator flux vector $\left(\theta_{s}\right)$ is obtained as follows;

$$
(2 \mathrm{~N}-3) \frac{\Pi}{6} \leq \theta(\mathrm{N}) \geq(2 \mathrm{~N}-1) \frac{\Pi}{6}
$$

where $\quad \mathrm{N}=1,2, \ldots \ldots, 6$

The motor developed torque is given by:

$$
\mathrm{T}_{e}=\frac{3}{2} \mathrm{P}\left(\mathrm{I}_{\beta s} \psi_{\alpha s}-\mathrm{I}_{\alpha s} \psi_{\beta s}\right)
$$

where $P$ is the pole pairs number.

The most significant feature of this algorithm is that it does not employ speed adaptation and, therefore, it is immune to speed estimation errors. This quality is important at very low speed operation and in drive systems that don't need the speed estimation at all. Moreover, using such hybrid voltage-current model is helpful towards increasing the overall system robustness.
However, even with this hybrid voltage-current method, the stator flux estimation is still sensitive to stator resistance detuning especially at low speeds. Stator resistance is not always constant but it changes due to temperature variations. The variation of the stator resistance deteriorates the performance of the DTC drive by introducing errors in the estimated stator flux magnitude and its phase angle and consequently in the electromagnetic torque. In order to deal with this difficulty, a stator resistance adaptation mechanism has been implemented. This allows a more reliable DTC, especially at low speeds.

\section{STATOR RESISTANCE ADAPTATION}

Among other variables of the machine, the stator current vector is highly affected by the stator resistance variation. The stator current magnitude is determined by the torque and flux commands. This means that, for a constant flux and torque, the stator current command is only dependent on the stator resistance of the machine. Therefore, any change in stator current indicates a change in stator resistance [16].

A block diagram of the proposed stator resistance adaptation scheme is shown in Fig.3. It is based on the principle that the error between the measured feedback current and its command value is proportional to the stator resistance variation. The incremental value of the stator resistance for correction is obtained through a PI controller. This incremental value, $\Delta \mathrm{R}_{\mathrm{s}}$ is continuously added to the previously estimated stator resistance, $R_{s 0}$. This final signal is the updated stator resistance and can be used directly by the controller. The stator resistance adaptation algorithm shown in Fig.3 requires the stator current command. It is derived from the dynamic equations of the induction motor in the synchronously rotating reference frame using the torque command and stator flux command as follows:

$$
\begin{aligned}
& \mathrm{I}_{\mathrm{qs}}^{*}=\frac{4 \mathrm{~T}_{\mathrm{e}}^{*}}{3 \mathrm{P} \psi_{\mathrm{s}}^{*}} \\
& \mathrm{~L}_{s}^{2} \mathrm{I}_{d s}^{* 2}-\mathrm{L}_{s} \psi_{s}^{*} \mathrm{I}_{d s}^{*}(1-\mathrm{D})+\mathrm{L}_{s}^{2} \mathrm{I}_{\mathrm{qs}}^{* 2}-\mathrm{D} \psi_{s}^{*}=0 \\
& \text { where } \quad \mathrm{D}=\frac{\mathrm{L}_{\mathrm{s}} \mathrm{L}_{\mathrm{r}}}{\mathrm{L}_{\mathrm{m}}^{2}-\mathrm{L}_{\mathrm{s}} \mathrm{L}_{\mathrm{r}}}
\end{aligned}
$$

Finally, the magnitude of the stator current command $I_{s}^{*}$ is calculated using Eqns (23) and (24) as:

$I_{s}^{*}=\sqrt{I_{q s}^{* 2}+I_{d s}^{* 2}}$ 


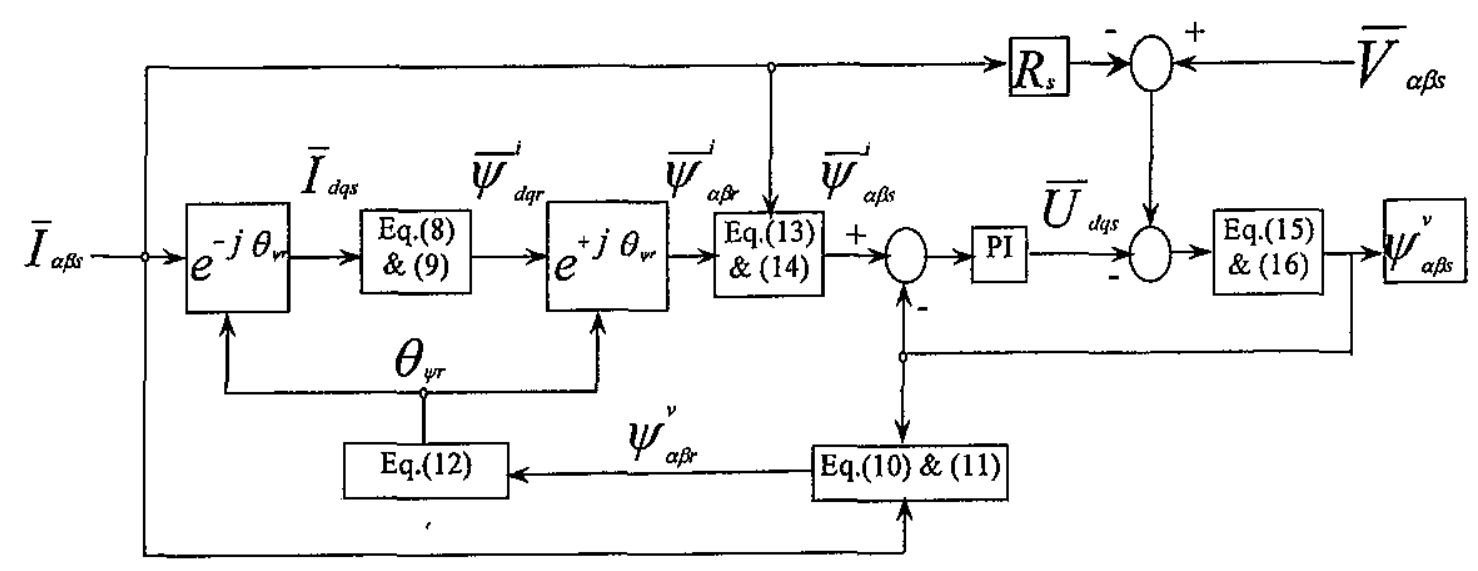

Fig.2 Block diagram of the hybrid stator flux estimator for the DTC drive

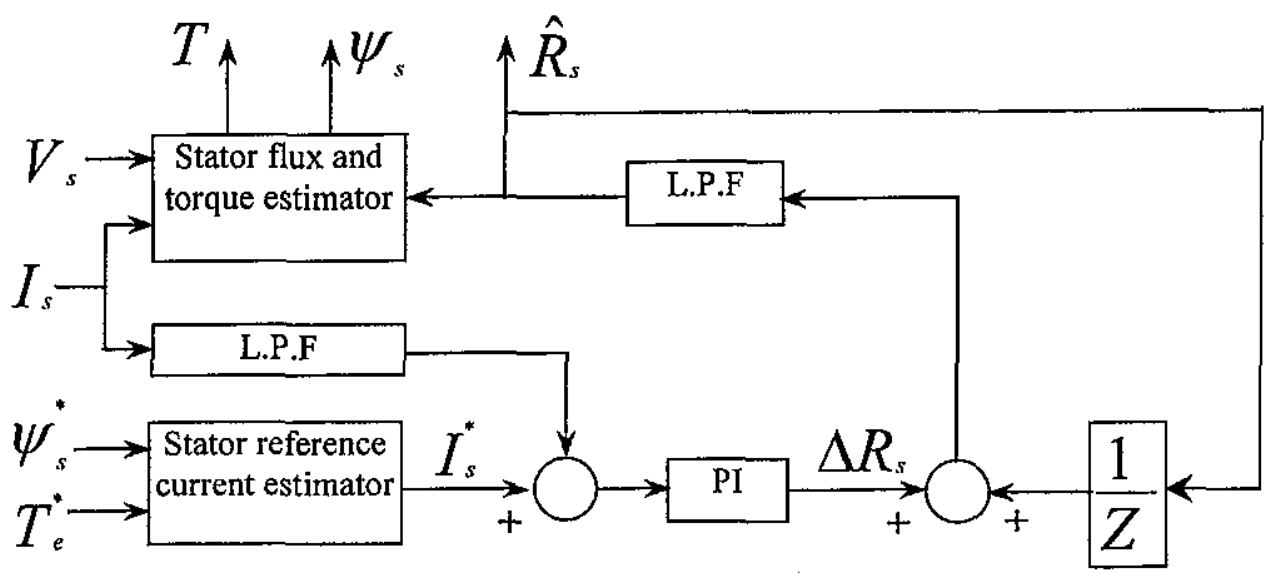

Fig. 3 Block diagram of the adaptive stator resistance tuning.

\section{SIMULATION RESULTS}

It is a usual practice to carry-out a computer simulation for the drive system to predict its performance before its real time implementation. A complete DTC drive system with a tuned voltagecurrent stator flux estimator as that shown in Fig.1 has been simulated by MATLAB/SIMULINK in order to verify its steady state and dynamic performances. The motor parameters used in the simulation are given in the Appendix.

\subsection{Steady-State Behavior}

The steady-state behavior of the proposed DTC system was investigated for both high and low speed ranges. Reducing the starting current with fast speed response is an essential objective and is considered one of the basic requirements for high performance. This can be achieved using a starting procedure such as ramp speed command. The acceleration time or the slope of ramp speed reference depends on the controller parameters and load conditions.

\subsubsection{High Speed Results}

The starting behavior of the motor at ramp acceleration with a load torque of $6 \mathrm{Nm}$ is shown in Fig. 4. It can be noticed that the rotor speed is accelerated smoothly and follows its speed command with minimum overshoot and nearly zero steady-state error as shown in. Fig.4-a. Figure 4.b shows the motor torque response which is quite fast. Also, Fig. 4.c shows the phase current response. It has a sinusoidal waveform with a limited starting value.

Figure 4.d shows the stator q-axis flux versus $d$-axis flux trajectory in the stationary reference frame. After an initial transient, the stator flux locus quickly becomes circular. The response of stator flux magnitude is shown in Fig. 4.e. It should be noted that it perfectly tracks its commanding value $(0.85$ Wb). 


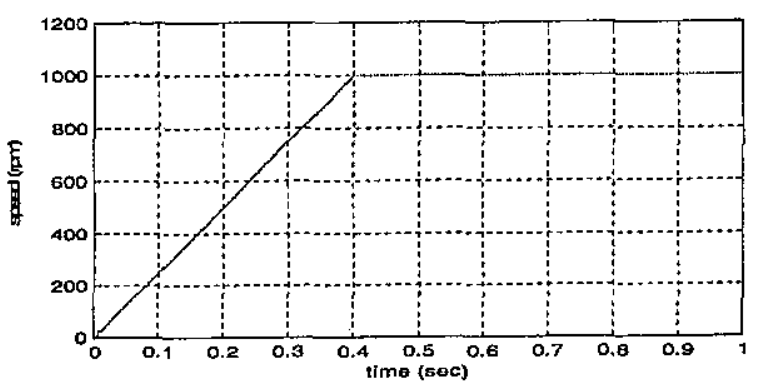

(4-a) Motor speed response.

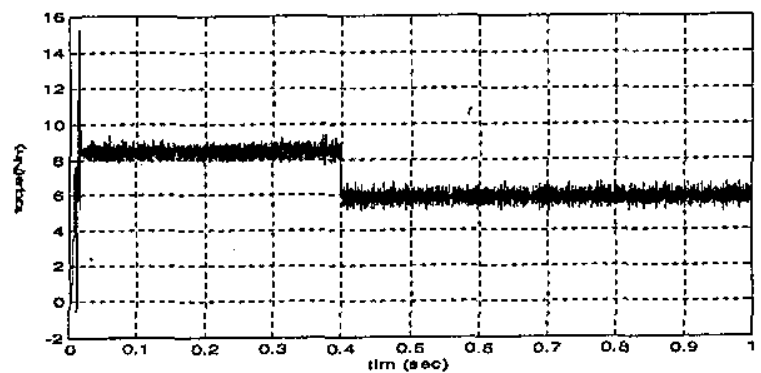

(4-b) Motor torque response.

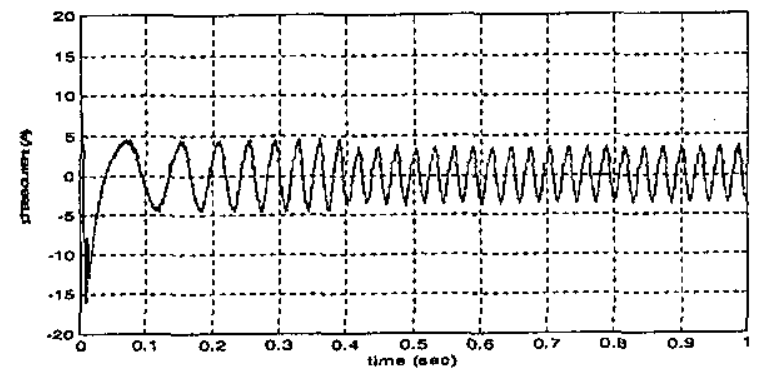

(4-c) Phase current response.

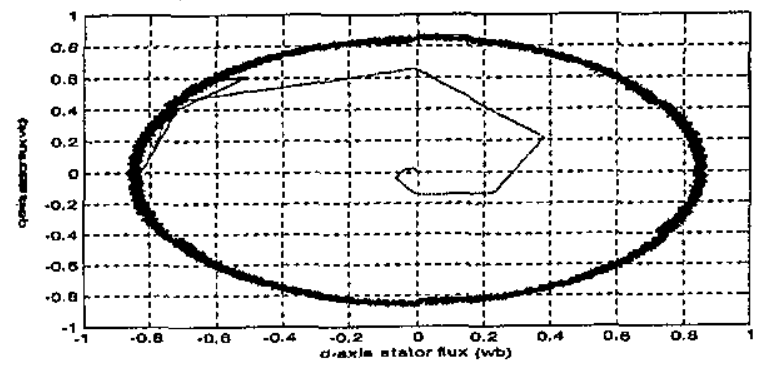

(4-d) Trajectory of the $d$ - and $q$ - axes stator flux

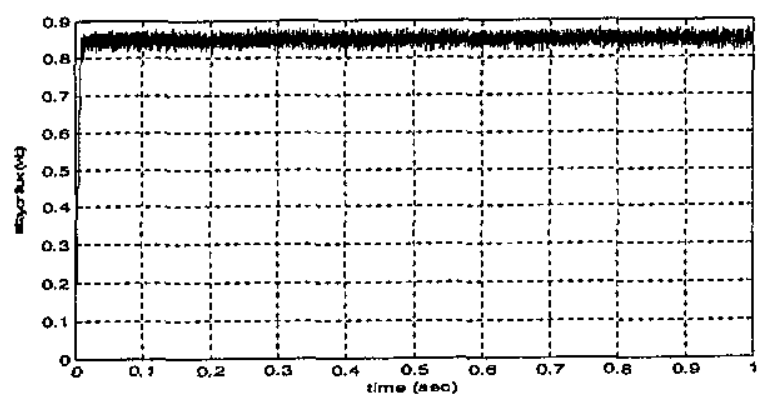

(4-e) Magnitude of estimated stator flux

Fig. 4. Starting performance at high speed with ramp speed command.

\subsubsection{Low Speed Results}

The performance of the proposed drive system has been tested also at low speed. The starting behavior of the motor at ramp speed reference of $100 \mathrm{rpm}$ with the same load torque of $6 \mathrm{Nm}$ is shown in Fig. 5. It is noticed that the motor starts with minimum overshoot as shown in Fig. 5-a. It is possible to see that, even at very low speed, the developed electromagnetic torque reaches its required value very fast as shown in Fig. 5-b, and the stator current shows sinusoidal waveform as shown in Fig. 5-c. Figure 5.d shows the stator q-axis flux versus d-axis flux trajectory in stationary reference frame. After an initial transient, the stator flux locus quickly becomes a circle, where the amplitude of the stator flux can perfectly track its commanding value $(0.85 \mathrm{~Wb})$ as shown in Fig. 5.e. From Figs $4 \& 5$ it can be concluded that the proposed voltage-current stator flux estimation model based direct torque control is an effective algorithm for the control of an inverter-fed induction motor at high and low speeds.

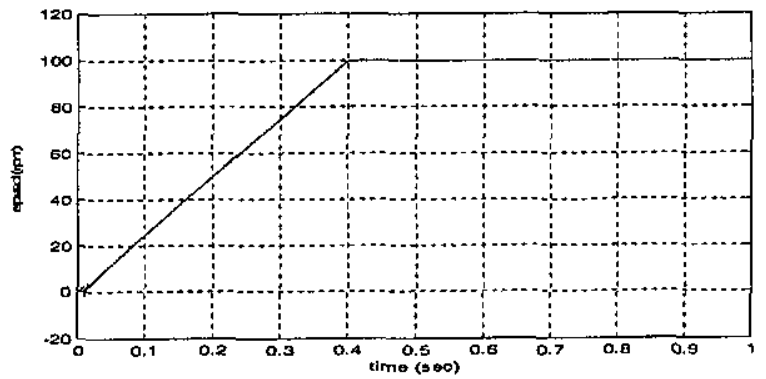

(5-a) Motor speed response.

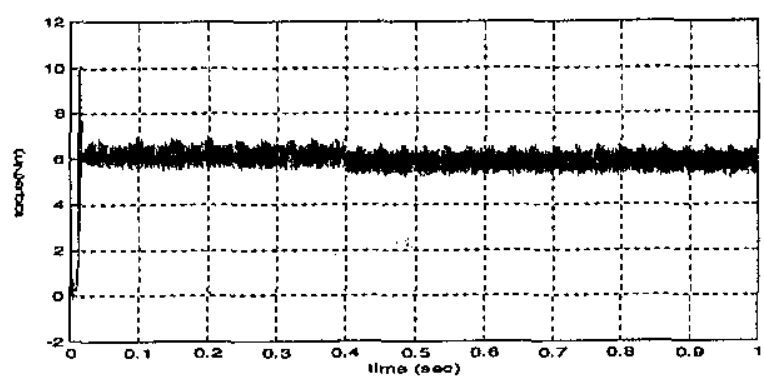

(5-b) Motor torque response.

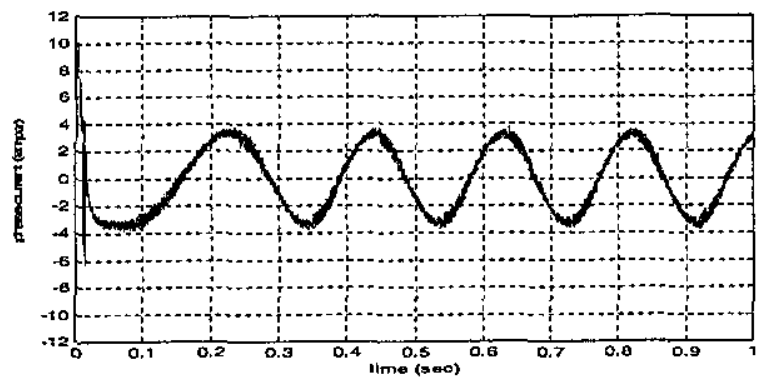

(5-c) Phase current response. 


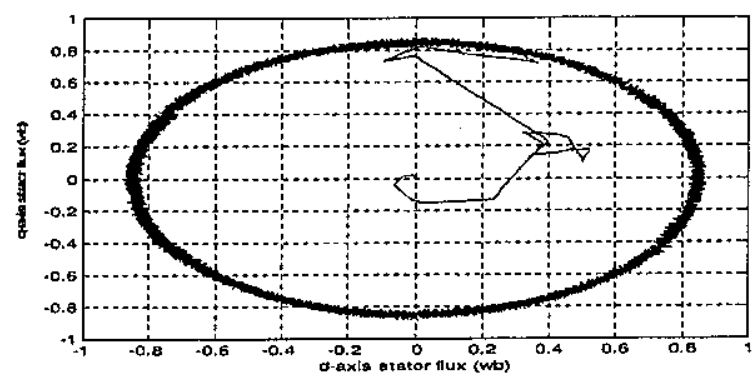

(5-d) Trajectory of the d- and q-axes stator flux

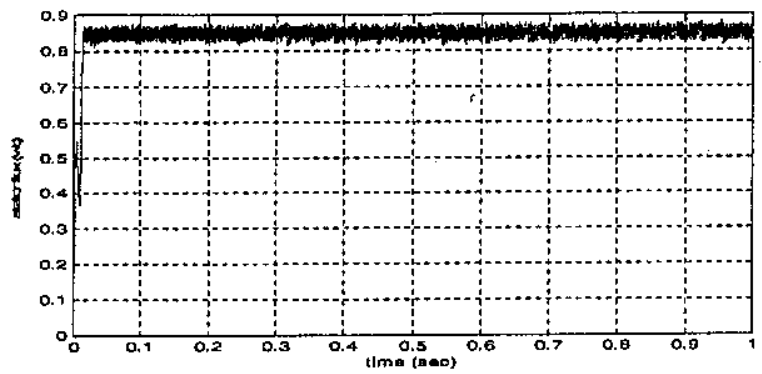

(5-e) Magnitude of estimated stator flux

Fig. 5. Starting performance at low speed with ramp speed command.

\subsection{Dynamic Performance}

For studying the dynamic performance of the proposed system, the drive has been subjected to a series of disturbances as step change in the speed reference and a sudden load impact. Simulation results of this study are given.

\subsubsection{Step Change in Speed Command}

The responses due to a step change in the speed command are used to evaluate the control system performance in terms of response time, overshoot, transient or steady state error and stability. The motor is subjected to a step decrease and a step increase in the reference speed to evaluate its performance in this case.

Figure 6.a. shows the rotor speed response to a command speed of $1000 \mathrm{rpm}$ with a load of $5 \mathrm{Nm}$. At $t=1 \mathrm{sec}$, the speed reference has been changed to $1020 \mathrm{rpm}$ and returned to $1000 \mathrm{rpm}$ after $500 \mathrm{~ms}$. It is noticed that the rotor speed is accelerated and decelerated smoothly to track its reference value with nearly zero steady state error. Figure 6.b exhibits the motor developed torque which shows a corresponding increase and decrease during the step changes of the speed reference. The motor phase current is shown also in Fig 6.c. The stator flux magnitude is kept constant at its command value as shown in Fig 6.d, which confirms the decoupled action of torque and flux control during dynamics.

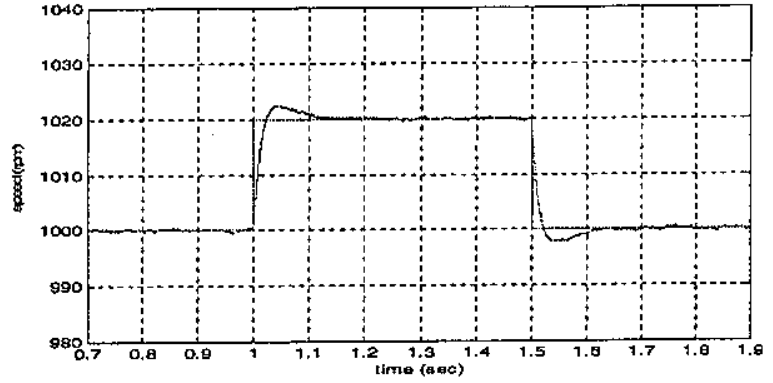

(6-a) Motor speed response.

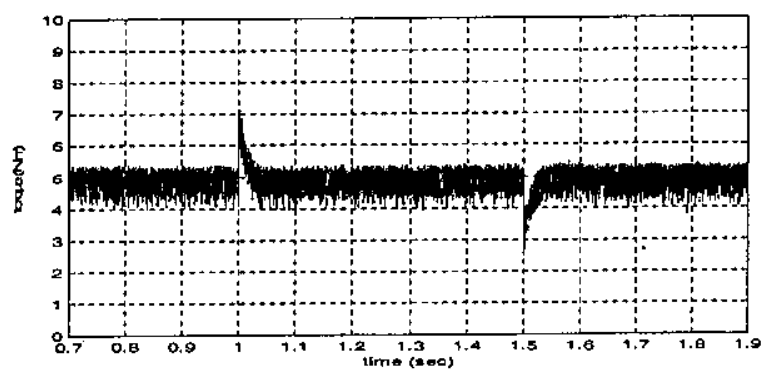

(6-b) Motor torque response.

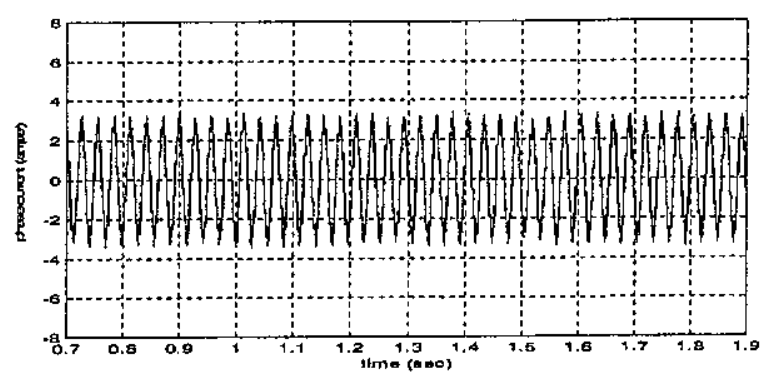

(6-c) Phase current response.

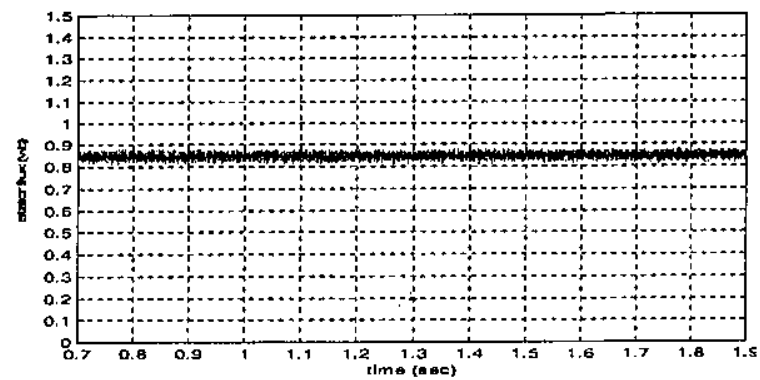

(6-d) Magnitude of estimated stator flux

Fig. 6 Drive response at step change in speed reference with load of $5 \mathrm{Nm}$

\subsubsection{Step Change in the Load Torque}

One of the most important features of the drive system is its ability to withstand step changes of the mechanical load torque applied to the motor. A highperformance control system should be of fast dynamic response in adjusting its control variables so as the outputs affected by load impacts are able to recover to the original status as soon as possible.

Figure 7 shows the dynamic response of the proposed control system under step changes of load torque. 
The motor was previously started with its full load and after $1 \mathrm{sec}$. the load torque is suddenly reduced to one-half for a period of $500 \mathrm{~m} . \mathrm{sec}$, and then increased to its original value. As it shown in Fig. 7.a, the developed electromagnetic torque shows very good response load changes. The rotor speed slightly changes at the instants of load changes as shown in Fig. 7.b, however, it is practically almost constant. The phase current changes corresponding to load torque, however its waveform is almost sinusoidal as shown in Fig. 7.c. The stator flux is always maintained constant at its command value during torque transition as shown in Fig. 7.d.

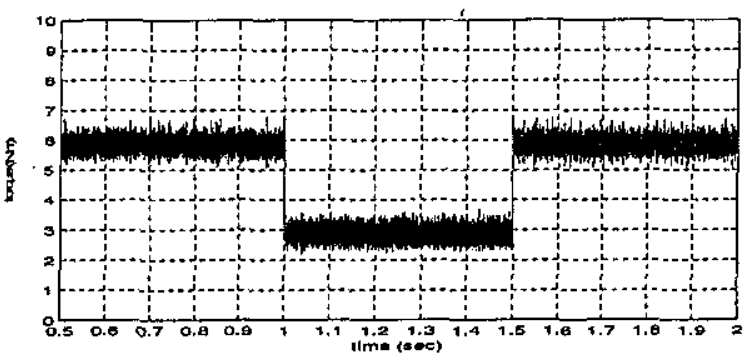

(7-a) Motor torque response.

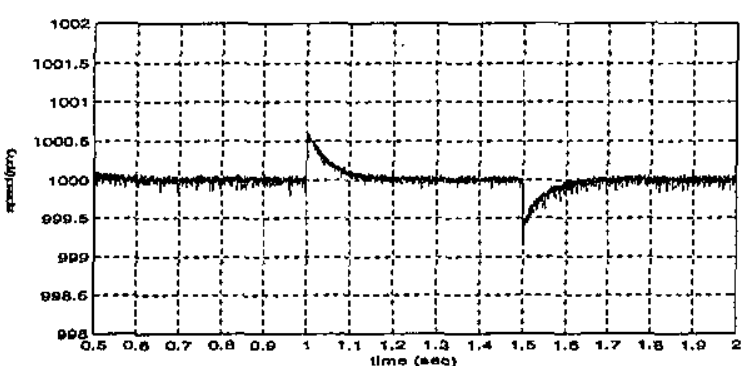

(7-b) Motor speed response.

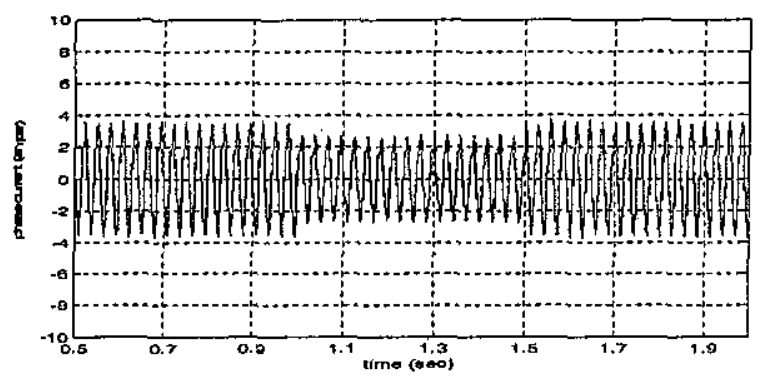

(7-c) Phase current response.

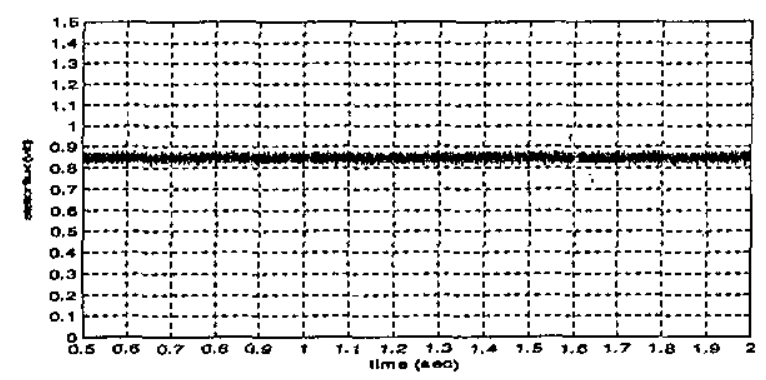

(7-d) Magnitude of estimated stator flux

\subsection{Stator resistance adaptation results}

A mismatch between the controller set stator resistance and its actual value can cause instability of the drive system. To study the effect of stator resistance variation on the drive, it was assumed that a step change occurs from its nominal value to 1.5 its nominal value after $3 \mathrm{sec}$. Simulation results are shown in Fig. 8. It is observed that as the stator resistance increases, the input current decreases, which decreases the stator flux and electromagnetic torque, respectively. The controller has an opposite effect in that the decreased current causes decreased stator voltage drop, resulting in higher stator flux and torque estimation. When they are compared with their corresponding command values they gave larger flux and torque errors leading to a run off condition. A resistance adaptation is so important to avoid this problem.

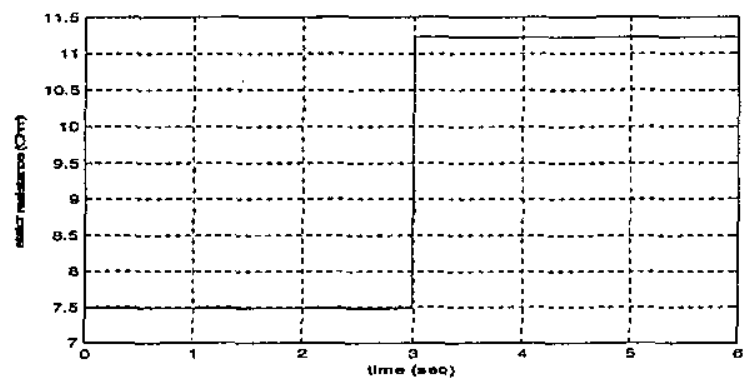

(8-a) Stator resistance variation.

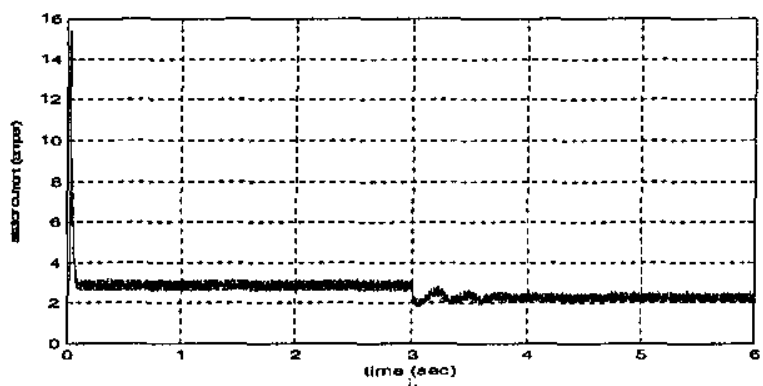

(8-b) Stator current magnitude variation.

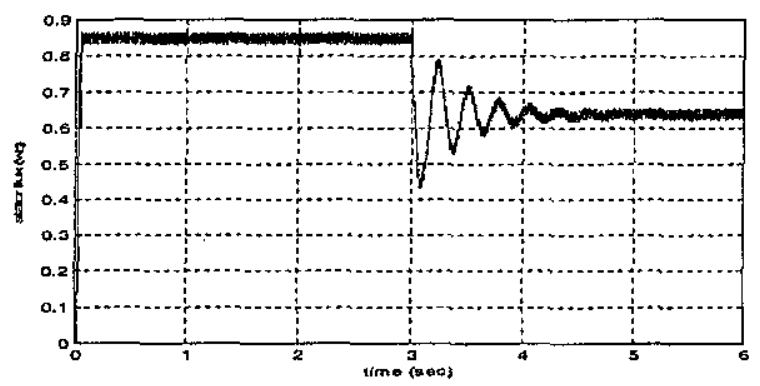

(8-c) Stator flux magnitude variation.

Fig. 7 Drive response due to step change in the load. 


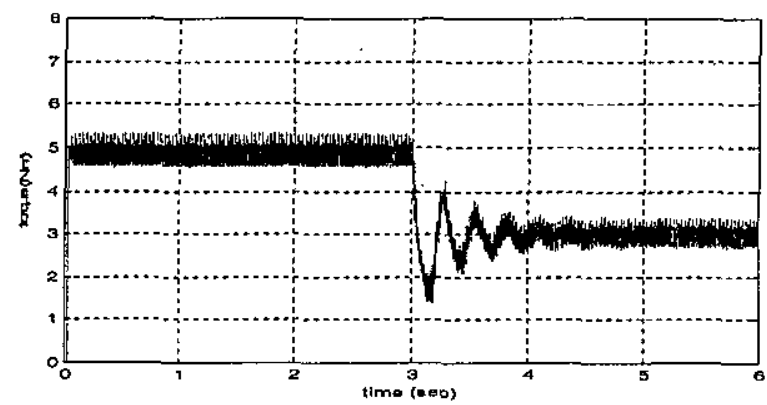

(8-d) Electromagnetic torque variation.

Fig. 8 The overall performance of the drive system without stator resistance adaptation.

Figure 9 shows the simulation results for an assumed step change in stator resistance. However, in a compensated drive system, it can be noted that the stator resistance adaptation assists restoring a precise and accurate estimation of stator flux magnitude as shown in Fig. 9.b. Also, the developed electromagnetic torque is very well regulated due to stator resistance adaptation as shown in Fig. 9.c.

Figure 10 shows the actual and estimated stator resistance of the machine using the proposed stator resistance adaptation scheme. As shown, the estimated stator resistance quickly tracks the actual value of the machine.

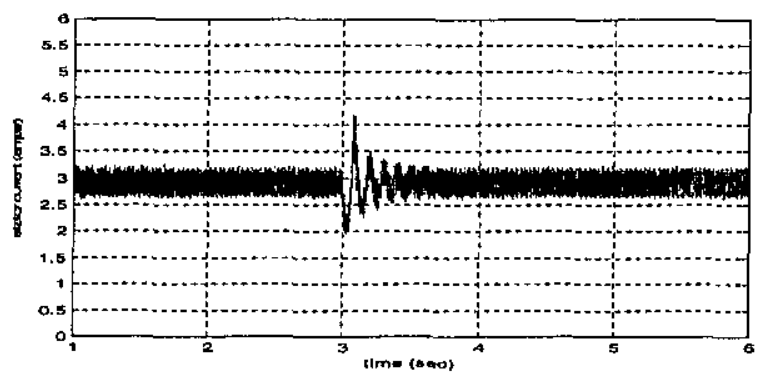

(9-a) Stator current magnitude variation.

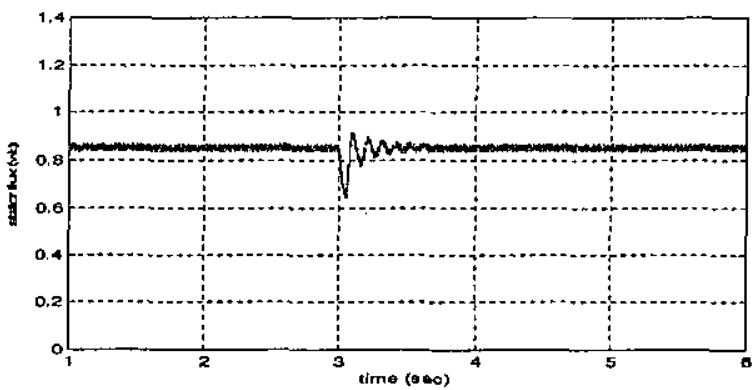

(9-b) Stator flux magnitude variation.

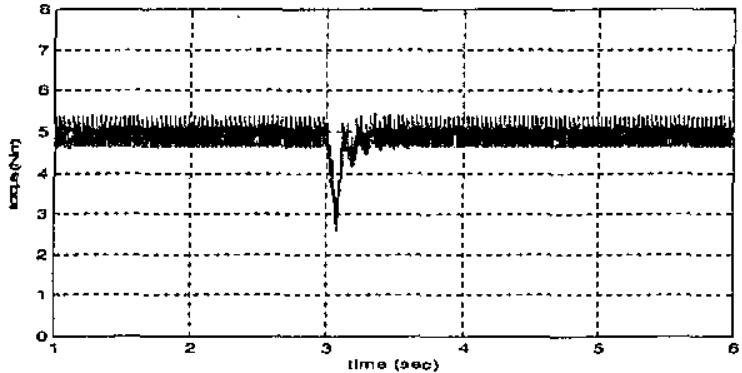

(9-c) Electromagnetic torque variation.

Fig. 9 The overall performance of the drive system with stator resistance adaptation

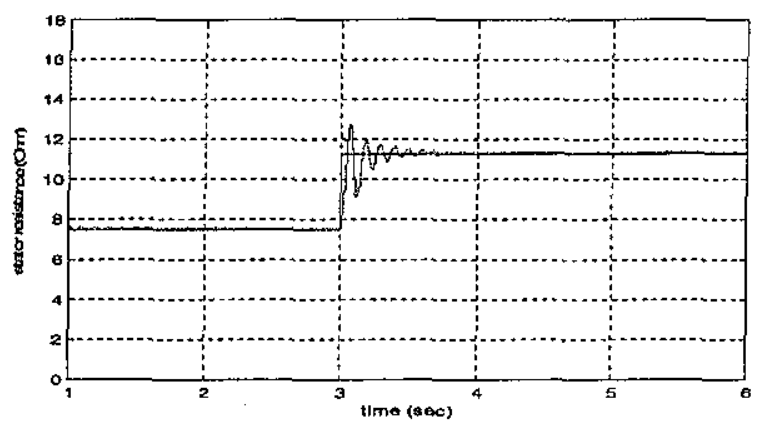

Fig. 10 Actual and estimated stator resistance

\section{CONCLUSIONS}

The paper has presented a control scheme for direct torque controlled induction motor drive, which provides a good torque and flux control over the entire speed range. An improved hybrid, closed-loop stator flux observer is proposed. It is based on the terminal quantities and does not require speed adaptation. The proposed method combined two estimators thus eliminating all existing restrictions for stator flux estimation. It enables smooth operation at both very low and high speed, while maintaining full dynamic controllability. The problem related to the stator resistance variation has been discussed. An adaptive resistance estimator utilizing only the existing stator current feedback has been introduced. The simulation was successfully carried out and the results confirm the precision of the proposed method.

\section{REFERENCES}

[1] I. Takahashi, T. Noguch, "A new quick- response and high- efficiency control strategy of an induction motor," IEEE-IAS, Vol. 22, pp. 820827, Sept. /Oct. 1986.

[2] M. Depenbrok, "Direct self-control (DSC) of inverter-fed induction machine," IEEE-PE, Vol. 3, pp. 420-429, Oct. 1988.

[3] G. Buja, "A New Control Strategy of the Induction Motor Drives: the direct flux and torque control," in IEEE Ind. Electronics Society Newsletter, Vol. 45, No.4, pp. 14-16, December 1998. 
[4] J.N. Nash, "Direct Torque Control, Induction Motor Vector Control without an Encoder," IEEE-IAS, Vol. 33, No.2, pp. 333-341, March/April 1997.

[5] L. Tang, L. Zhong, M. F. Rahman, and Yuwen $\mathrm{Hu}$, "A Novel Direct Torque Control for Interior Permanent-Magnet Synchronous Machine Drive with Low Ripple in Torque and Flux-A SpeedSensorless Approach ," IEEE-IAS, Vol. 39, No. 6, pp.1748-1756, November/December 2003.

[6] J. Holtz, J. Quan, "Sensorless Vector Control of Induction Motors at very low speed using a nonlinear Inverter Model and Parameter Identification," IEEE-IAS, Vol. 38, No. 4, pp.1087-1095, July/August 2002.

[7] Jansen, P. L., and Lorenz, R. D., "A physically insightful approach to the design and accuracy assessment of flux observers for field oriented induction machine drives," IEEE-IAS, Vol. 30, No. 1, pp. 101-110, Jan. /Feb. 1994.

[8] T. G. Habetlr, F. Profumo , G. Griva, M. Pastorelli, and A. Bettini, "Stator resistance tuning in a stator-flux field- oriented drive using an instantaneous hybrid flux estimator," IEEEPE, Vol. 13, No. 1, pp. 127-133, January 1998.

[9] C. Lascu, I.Boldea, F.Blaabjerg, "A Modified Direct Torque Control for induction motor Sensorless drive," IEEE-IAS, Vol. 36, No.1, pp. 122-130, Jan. /Feb. 2000.

[10] T. Okuyama, N.Hujimoto, and H. Hujii, "A simplified vector control system without speed and voltage sensors-effect of saturating errors of control parameters and their compensation," Electrical Engineering in Japan, Vol. 110, No. 4, pp. 129-139, 1990.

[11] R. J. Kerkman, B. J. Seible, T. M. Rowan, and D. Schlegel, "A new flux and stator resistance identifier for AC drive systems," Conf. Record, IEEE-IAS, Orlando, Florida, pp. 310-318, Oct. 1995.
[12] L. A. Cabrera, M. E. Elbuluk, and I. Husain, "Tuning the stator resistance of induction motors using artificial neural network," IEEE -PE, Vol. 12, No. 5, pp. 779-787, Sept. 1997.

[13] S. Mir, M. E. Elbuluk, and D. S. Zinger, "PI and fuzzy estimators for tuning the stator resistance in direct torque control of induction machines," IEEE -PE, Vol. 13, No. 2, pp. 279-287, March 1998.

[14] Takahashi,I., and Ohmori, Y., "High performance direct torque control of induction motor," IEEE -IAS, Vol. 25, No. 2, pp. 257-264, Mar./Apr. 1989.

[15] Bausch, H., Kanelis, K., Lange, B., and Zeng, $W$, "Torque control of synchronous and asynchronous drives without mechanical sensors," Proc. of ICEM , Paris France, pp. 324328, Sept. 1994.

[16] S. A. Mir, D. S. Zinger, and M. E. Elbuluk "Fuzzy controller for inverter fed induction machines," IEEE IAS, Vol. 30, No.1, pp. 78-84, 1994.

\section{APPENDIX}

The rated values and parameters for the machine used in the simulation study are given below.

$\begin{array}{ll}\text { Rated output power } & 1 \mathrm{~kW} \\ \text { Rated voltage } & 380 \mathrm{~V} \\ \text { Rated frequency } & 50 \mathrm{~Hz} \\ \text { No. of pole pairs } & 2 \\ \text { Rated speed } & 1430 \mathrm{rpm} \\ \text { Stator resistance } & 7.48 \Omega \\ \text { Rotor resistance } & 3.83 \Omega \\ \text { Stator self inductance } & 433 \mathrm{mH} \\ \text { Rotor self inductance } & 433 \mathrm{mH} \\ \text { Mutual inductance } & 411 \mathrm{mH} \\ \text { Rotor inertia } & 0.03 \mathrm{Kg} \cdot \mathrm{m}^{2}\end{array}$

